Percentage exact agreement (\%EA) versus reviewer type

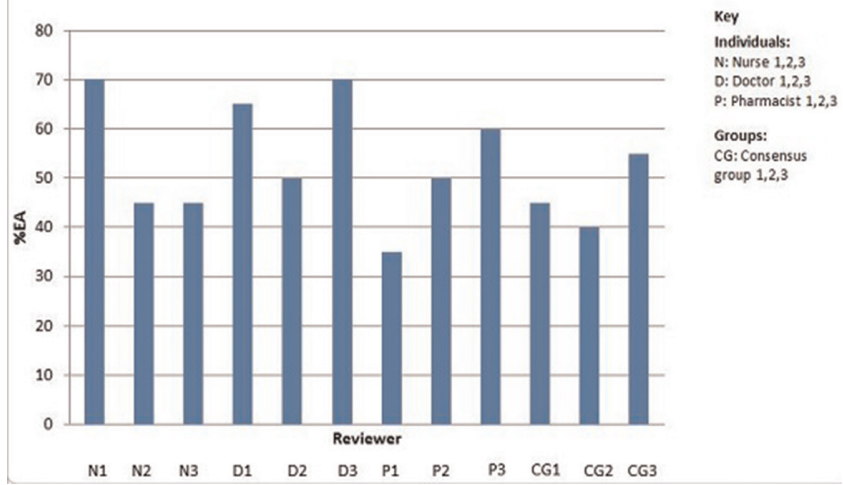

Abstract P0-0926 Figure 1

ethnographic approach was taken; the consensus meetings were overseen by a facilitator and non-participant observations of the meetings were recorded. Post consensus meeting semi-structured interviews were conducted with the group members. Qualitative and quantitative analyses were carried out. We examined the extent to which individuals and groups agreed with the 'gold standard' using percentage exact agreement (\%EA) (Figure 1).

Results Agreement ranged from 35-70\%. The mean agreement for individuals was $54 \%$ and $47 \%$ for the consensus groups.

Conclusion In assessing avoidability of ADRs individual assessments had better agreement with the 'gold standard' evaluation than group assessments. Qualitative analysis of meeting observations and participant interviews may help identify reasons for this and inform the optimisation of the LAAT for assessment of ADR avoidability.

\section{P0-0927 THE DIFFERENCE SPECTRUM OF ACTIVITY OF SYNTHETIC INTERFERON INDUCTORS}

${ }^{1} \mathrm{~V}$ Bulgakova, ${ }^{2} \mathrm{M}$ Dambrova, ${ }^{2} \mathrm{E}$ Makarova, ${ }^{2} \mathrm{R}$ Vilskersts, ${ }^{3} \mathrm{~A}$ Bevz, ${ }^{3} \mathrm{I}$ Prostyakov, ${ }^{3} \mathrm{~S}$ Nadorov, ${ }^{3} \mathrm{E}$ Osipova. 'Department of Scientific Research, Scientific Centre of Children Health, Moscow, Russia; 'Laboratory of Pharmacology, Latvian Institute of Organic Synthesis, Riga, Latvia; ${ }^{3}$ Department of Medical, Pharmstandard, Moscow Region, Russia

\subsection{6/archdischild-2014-307384.1548}

Objectives Until now the stimulating effects of these interferonogens have been shown for type I and II IFNs, however the data regarding induction of type III IFNs has not been available. Methods

The IFN $(\alpha, \beta, \gamma$ and $\lambda 2 / 3)$ inducing activities of low-molecular synthetic interferonogens tilorone (amixin), meglumine acridonacetate (cycloferon), sodium carboxymethylcellulose and gossypol conjugate (kagocel) are compared in CBA mice. Results

Administration of tilorone in comparison to cycloferon and kagocel has a significant dose-dependent effect on IFNs concentration in mice serum. Maximal level of all IFNs in serum was observed after $24 \mathrm{~h}$ of administration of tilorone (IFN $\alpha 176 \pm$ 10 and $398 \pm 12 \mathrm{pg} / \mathrm{ml}$ for the doses of 40 and $400 \mathrm{mg} / \mathrm{kg}$, IFN $\beta 8 \pm 4-110 \pm 6$, IFN $\gamma 4 \pm 1-46 \pm 10, \operatorname{IFN} \lambda 2 / 31337 \pm$ 93 and $2231 \pm 93 \mathrm{pg} / \mathrm{ml})$. Cycloferon and kagocel do not induce the increase of IFN $\alpha$, IFN $\beta$ and IFN $\gamma$ in mice serum.
The highest level of IFN $\lambda 2 / 3$ after introduction of kagocel at the both doses was seen after $48 \mathrm{~h}(616 \pm 135-382 \pm 46 \mathrm{pg} / \mathrm{ml})$. Administration of cycloferon at a dose of $150 \mathrm{mg} / \mathrm{kg}$ significantly stimulated IFN $\lambda 2 / 3$ level in serum after $72-120 \mathrm{~h}$ of administration (391 $\pm 31-388 \pm 80 \mathrm{pg} / \mathrm{ml})$. Cycloferon at the highest dose significantly increased the IFN $\lambda 2 / 3$ levels between $12-24 \mathrm{~h}$ after administration $(434 \pm 79-441 \pm 47 \mathrm{pg} / \mathrm{ml})$.

Conclusion Tilorone induces synthesis of type I and type II IFNs as well as type III IFNs (IFN $\lambda 2 / 3$ ) in serum, while administration of kagocel and cycloferon stimulates only type III IFNs (IFN $\lambda 2 / 3$ ) in serum. Tilorone (amixin) has the widest spectrum of activity and is the most promising of the studied interferon inducers.

\section{PO-0928 ROTAVIRUS GASTROENTERITIS AND MEDICATION PROFILE AMONG CHILDREN YOUNGER THAN 5 YEARS: HOSPITAL BASED TWO YEAR STUDY}

${ }^{1} \mathrm{~L}$ Jenny John, ${ }^{2}$ S Cheriathu, ${ }^{2} \mathrm{E}$ Ignatius Dsouza, ${ }^{2} \mathrm{M}$ Shamseldeen, ${ }^{3} \mathrm{~A}$ Mathur. ${ }^{1}$ Pharmacology, Gulf Medical University, Ajman, United Arab Emirates; ${ }^{2}$ Pediatrics, Gulf Medical University, Ajman, United Arab Emirates; ${ }^{3}$ Department of Microbiology, Gulf Medical University

\subsection{6/archdischild-2014-307384.1549}

Background and aims Rotavirus accounts for more than 50\% of gastroenteritis worldwide and leads to significant morbidity and mortality especially among children younger than five. The drug utilisation profile in rotavirus infection among the admitted children $<5$ years with gastroenteritis was studied.

Methods Cross-sectional hospital based study was carried out among children age $<5$ years admitted to Paediatric ward with Rotavirus gasteroenteritis (RVGE) from 2011-12. A data collection form (proforma) was used to record the demographic, clinical and medication related data. Statistical analysis was performed using SPSS version 20 software. Chi-square test and t- test were used to compare variables.

Results 240 cases $(24.7 \%)$ were Rotavirus positive among acute gastroenteritis (AGE) (Total: 970) among children $<5$ years. Amoebiasis accounted to 38 cases (4\%)

133 children $(57 \%)$ were males; $38 \%$ were of the age group 1-2 years and $24.2 \%$ less than 1 year.

Mean duration of hospital stay was 2 (1 day).

768 drugs were prescribed in 240 children with RVGE.

Median number of drugs prescribed was three (range: 1-5 drugs).

Majority received 2-3 drugs (60.8\%).

H-2 receptor blockers, Anti-emetics, antipyretics and probiotics were the major drug classes prescribed.

Among individual drugs, Ranitidine, Metoclopramide and Paracetamol were frequently utilised.

Of 240 cases, 39 children received treatment prior to hospital visit.

Among 38 Amebiasis cases, Metronidazole was prescribed in all children.

Conclusion Rational use of medications was observed in all cases of Rota virus gastroenteritis in the present study. Rotavirus testing is important tool to differentiate from other GE and thus avoid irrational use of drugs. 